\title{
The Impact of Strategic Decision-Making on Enhancing Competitive Capability: Case Study of the Royal Jordanian Airlines
}

\author{
Majda S. Rteimeh ${ }^{1}$ \\ ${ }^{1}$ Jadara University, Amman, Jordan \\ Correspondence: Majda S. Rteimeh, Jadara University, Amman, Jordan. E-mail: majdaarteimeh@yahoo.com
}

Received: January 20, 2019

Accepted: February 13, 2019

Online Published: February 19, 2019

doi:10.5539/ijbm.v14n3p148

URL: https://doi.org/10.5539/ijbm.v14n3p148

\begin{abstract}
The study aimed at identifying the extent of efficiency of the strategic decision making (the determination of the problem, the gathering of the information on the problem, decision-making, the monitoring of the implementation of the decision-making, and the circulation of the realistic results of the decision) and demonstrating their impact in enhancing the competitive capability of the Royal Jordanian Airlines. This study followed the descriptive and the analytical approach relying on a questionnaire that reached a sample of 167 employees working at the various administrative levels of the company. The results of the study showed that there is a medium degree of efficiency for strategic decision-making and a medium degree of competitiveness. The results also showed a statistically significant impact for each of (gathering information about the problem of enhancing the competitive capability of the Royal Jordanian Airlines, decision-making, and circulating the realistic results of the decision) in enhancing the competitive capability of the Royal Jordanian Airlines.
\end{abstract}

Keywords: competitive capability, royal Jordanian airlines, strategic decision

\section{Introduction}

The recent changes that the world has witnessed have affected the administrative practices and the nature of organizational relationships in institutions and organizations in all their forms. The competitive environment has become highly complex and competitive (Lalaimeh, 2015).

Decision-making is considered one of the most important things that affect the position of the institutions and organizations in the market, especially if these decisions are related to the strategic decisions (Issawi, 2015).

Lalaimeh (2015) had pointed out that the conditions and variables, that accompanied diversity and restriction in the internal and external environment factors of today's organizations, has necessitated the presence of intelligent leaders and thinkers that have intellectual capabilities and non-standard skills that depends on the bases of developing knowledge, experience and its principles.

Strategic decision-making is one of the most important topics that draw the attention of many researchers because these decisions have an effective impact on the work of organizations, which in turn affects the economic system of countries. The importance of strategic decision-making is that it is related to the future side and the time dimension. It also includes fields of life in all its forms that are related to the long term and future perspectives (Hamza, 2008).

Issani and Jabri (2016) noted that strategic decision-making is one of the important links in the process of strategy-drafting because it is based on the results of the strategic analysis process undertaken by the institution where a set of available alternatives is being created, and the strategic decision is being chosen and put in force for the future period in order to achieve its intended objectives as it will lead the institution to move towards a better position.

Regarding the competitive capability, the concept of the competitiveness in our modern economy has played an important role in shaping the challenges faced by the economies of the countries and companies in an increasingly open world that is influenced by the changes surrounding it, as countries compete among themselves for wining markets for their commodity and service products in the world (Munir, 2006).

Hammoud (2015) pointed out that the attention given to competitiveness is necessary in order to rise to a better level on the global level, both for countries and institutions. Accordingly, the attention given to the 
competitiveness of any service will have an impact in one way or another in enhancing the competitiveness on the international level, both for the institution or the state.

The researcher believes that competitiveness is no longer depends on the provision of services of high quality only, but depends on a lot of elements, the most important of which is the ability to provide what distinguishes the organization from other competitors. In order to achieve this, an integrated analysis of the external environment and internal organization must be done and then make the appropriate decision according to that environment.

Royal Jordanian Airlines was established under a Royal order in (1963). It was named Alia Company, and then became a limited liability company. The company's operational activity was to carry out all air transportations inside and outside the Kingdom and to receive and transport aircrafts landing in and departing from the Kingdom's airports. The Civil Aviation Authority granted the Company the exclusive rights to operate regular international flights, which ended in 2010. The Royal Wings Company is considered its affiliated company (National Portfolio Securities plc, 2009).

Royal Jordanian Airlines is facing issues with its competitiveness in the light of open skies policies that have led to an increase in the sharpness of the competition in air transportation and the suspension of the laws that grant the right of exclusive air transportation. According to the importance of strategic decision-making and competitiveness, and the problems faced by Royal Jordanian, the current study focused on the impact of strategic decision-making in enhancing the competitive capability of the Royal Jordanian Airlines.

\subsection{Problem Statement}

The Royal Jordanian Airlines is facing problems in its ability to make profits since long periods. Perhaps the most thing that illustrate that is what was published in the alrai Jordanian newspaper $(3 / 8 / 218)$, which showed that the director general and chief executive of the company, "Peshler" is going to lay off (75\%) of the staff of the company to reduce expenses, as the profits of the company keep falling due to the intensity of competition in the light of the proliferation of airlines and their ability to provide what is required by the traveler at the lowest cost and at an appropriate quality level. Perhaps the political and security problems faced by the countries surrounding Jordon have led to the aggravation of the problems of the Royal Jordanian Airlines, which began with the laws that opened the door for the competition and stopped the exclusive right of transportation of the Royal Jordanian Airlines.

\subsection{Research Questions}

According to the importance of the efficiency and effectiveness of strategic decision in achieving competitive capability, the subject of the current study centers on answering the following questions:

The main question:

What is the impact of strategic decision-making in enhancing the competitive capability of the Royal Jordanian Airlines?

The sub-questions:

1. How effective is the strategic decision-making (the determination of the problem, the gathering of the information on the problem, decision-making, the monitoring of the implementation of the decision-making, and the circulation of the realistic results of the decision) in the Royal Jordanian Airlines?

2. What is the competitive capability level of the Royal Jordanian Airlines?

3. What is the impact of the efficiency of the strategic decision-making in enhancing the competitive capability of the Royal Jordanian Airlines?

\subsection{Aims of Study}

1. Identify the efficiency of the strategic decision-making (the determination of the problem, the gathering of the information on the problem, decision-making, the monitoring of the implementation of the decision-making, and the circulation of the realistic results of the decision).

2. Identify the impact of the strategic decision-making in enhancing the competitive capability of the Royal Jordanian Airlines.

\section{Literature Review}

\subsection{Previous Studies}

The research of (Lalaimeh, 2015) aims at clarifying the importance of strategic intelligence in the decision-making 
process of the institution. The research was made on the Ferital institution, based on the view of the Director of the institution, where he was interviewed, and the descriptive and analytical approaches were applied in this study.

The study reached a number of conclusions, the most important of which is that the institution depends to a great extent on the application of the dimensions of strategic intelligence in the decision-making process in the institution. It also concluded that the stages of strategic intelligence are represented in the framework of supporting the decision-making process in the following: Determining the need of the information, gathering information, processing the information, circulating the information in order to make the decision. In light of these conclusions, the study recommended the need to work on the diagnosis of the strategic position of the institution by relying on the offices of research and consulting, which carries the task of applying the strategic matrixes to determine the strategic position of the institution.

The study of Issani and Jabri (2016) aimed at understanding the role of the decision support systems in strategic decision-making in the economic institution (Omar Bin Omar Mills) in Guelma. The study was based on the descriptive analytical approach, as well as the statistical method.

The sample of the study consisted of 125 workers from the institution where the questionnaires were distributed to them. The study reached several conclusions; the most important of which was the awareness of the institution that shows the effective role that results from its application in the institution and the benefits resulting from it, as well as the availability of possibilities that help its application. This makes the institution ready to keep pace with the rapid technological developments. The study summarized several recommendations, the most important of which is the training as well as attracting experts and specialists in the field of decision support systems in order to contribute in the success of its application within the institution.

Al-Otoum's study (2009) aimed at shedding the light on the state of the pharmaceutical industry in Jordan and at showing the impact of the organization's mission and its components in achieving the competitive advantage in the Jordanian pharmaceutical industry. The study population consisted of (5) Jordanian pharmaceutical companies. The study sample consisted of the managers working in these companies. The study reached several conclusions, the most important of which was that there was an impact at the level of significance (0.05) for the adoption of quality, research and development, meeting the customer needs and the attention to human resources in the mission of Jordanian pharmaceutical companies and achieving competitive advantage. In light of these conclusions, the study recommended that the mission of the Jordanian drug companies should not be mere slogans, but should be translated into programs and actions in order for the customers to feel the results of these companies.

Hamod's study (2015) aimed at clarifying the concept of competitiveness, its definition, how to measure it and its affection by the global economic environment. The study was based on the analytical descriptive approach in addition to the statistical method. The study focused on studying the state of the Syrian cotton products and the most important indicators of the competitiveness of these products in the context of the liberalization of the international trade during the period between (2000 and 2010). The study reached several conclusions, the most important of which is the possibility of Syria, under the signed international, regional and bilateral agreements or which are seeking to sign, to expand the exports of the Syrian cotton products in the foreign markets. The study summarized several recommendations, the most important of which is the necessity of having a technical scientific center specialized in the establishment of industrial policies related to cotton products and its development and providing all consultations related to cotton products under the supervision of the Ministry of Industry and with the participation of the private sector.

The study of Al-Hajraf (2011) aimed at investigating the impact of the strategy of the organizations in improving the competitiveness of Kuwaiti commercial banks. The study sample consisted of (197) employees from three Kuwaiti commercial banks, where the questionnaire was distributed as a study instrument. The study reached several conclusions, the most important of which is that the impact of the organizations' strategy in improving the competitiveness of the commercial banks in Kuwait was high. The conclusions showed a high level of impact for the growth strategy in addition to the impact of the strategy of regression in improving the competitiveness of commercial banks in Kuwait. The study summarized several recommendations, the most important of which is that the Kuwaiti commercial banks need to adopt the business strategy, in all its kinds, in their administrative practice.

The study of Hamzah (2008) aimed at demonstrating the relation between strategic decision-making and the banking performance. A set of financial ratios was used by the banks to conduct the analysis. The study included a sample of Iraqi public banks consisting of 21 banks during the period between(1999 and 2002).The study 
reached several conclusions, the most important of which was that the strategic decisions made to increase the capital were not successful and constituted a burden on the bank rather than a benefit to it, in addition to the lack of an inclusive strategy specifying the work of the bank, therefore strategic decisions in the field of investment is inefficient which weakened the achieved results. The study summarized several recommendations, the most important of which is the development of an inclusive strategy for the bank's work and clear plans for investment and attracting deposits to ensure the achievement of the bank's objectives.

Peixoto et al. (2017) study aimed at linking the use of the decision support system used by senior executives with the perceived benefits of intelligence, organizational structure and strategic decisions in the Brazilian largest companies. The questionnaire was used as an instrument to gather the primary and private data in order to test the hypotheses. The study reached several results, the most important of which is that the repeated use of the decision support system is positively related to the mental model, the availability of information and the expansion of analysis. This may indicate that the Brazilian leaders realize that understanding the problems in a better way can affect their mental models.In light of these results, the study recommends that the learning process of the employees should be continued. Thus if their knowledge has increased, the ability to understand the availability of information and to expand the analysis will increase.

The study of Esmaeili (2014) aimed at identifying not only the effective elements of strategic intelligence, strategic decision- making and strategic planning, but also the impact of strategic intelligence on strategic decision-making and strategic planning in organizations and companies that use the smart system in Khorramabad. According to the results, this study is an analytical survey. The study population consisted from the companies and institutions that use the smart systems in Khorramabad, which was estimated by (150) using the Cochran formula random sampling method. The questionnaire was used as a research tool. Both the structural equation approach and the AMOS 18 program were used to study and test the hypothesis. The study reached a number of results, the most important of which is that the strategic intelligence has a positive and objective impact on strategic decision making and strategic planning in companies and organizations that uses smart systems in Khorramabad. Under these findings, the study recommended the need to recognize the effective elements of the strategic intelligence, human resource information, organizational process, technology, informatics, financial resources, competitors, and the intelligence of the customers.

\section{The Theoretical Literature}

According to the fierce competition that the world witnesses today, especially with the emergence of the concept of globalization, the modern business environment requires the senior management of the organizations to recognize the need to develop their strategic decisions according to correct and flexible mechanisms and methods. The strategic decision is considered one of the most important issues in the process of strategy-drafting as it depends on the results of the strategic analysis process carried out by the organizations, where a set of available alternatives is established, the best of which is the strategic decision from the administration's point of view that will be put in force for the future period in order for the organizations to achieve its intended objectives which will move the organizations to move towards a better position. (Elghaliby, 2012)

Decision-making is one of the most important functions of the managers in the organization. Without decisions, the Organization cannot exist nor achieve any success. Although there are many different definitions in the literature for the decision-making process, they mostly refer to it as an ongoing process that the managers have to undertake and it takes most of their interest, it represents the basis for the existence of the business and its performance (Gigerenzer, 2001).

Among the different decisions of the managers, strategic decision-making is the most important and plays vital roles in any organization, it is a centralized management activity in all types of business organizations; large and small, for-profit, non-profit, private and public, it is also a long-lasting process, largely unregulated, complex, risky and has a major impact on the future of the organization (Ivan \& Ivana, 2012).

(Ahmed et al, 2014) indicated that making the right decisions is not only limited to what the organization wants, but also includes what it should do. On the other hand, the consequences of not making a decision can be more severe than making the wrong decision. Strategic decision-making is very important because of its characteristics.

The importance of strategic decision-making stems primarily from the impacts on the organizational performance. In particular, successful strategic decision-making enables the organization to maintain a competitive position, to adapt the internal processes to the external environment and to overcome threats and challenges. On the other hand, one weak strategic decision can lead to the demise of an organization. So it is not surprising that there is an increasing interest in the nature of strategic decision making among researchers around 
the world (Ivan \& Ivana, 2012).

Strategic decision-making deals with the process of the implementation and the factors influencing the process. Several strategic decision concepts provide details that link the strategic decision-making to issues such as the organization's design and planning strategies, merger and acquisition initiatives, large investments in new products or markets, making or buying options and internal reorganization process (Elbanna \& Child, 2007).

The researcher believes that since the process of decision-making represents the backbone of the organization, it must be done through leaders that have enough accumulated specific experiences, the knowledge and the ability to analyze and invest resources and realistic future perceptions about the various environmental variables.

\subsection{Strategic Decision}

The concepts of the strategic decision have varied with the multiplicity of its definitions. So in order to identify the concept of the strategic decision, we begin first with the concept of the decision in general.

The decision has been defined as "what the opinion has upheld and issued by an oral or written order or field action. This is after the determination, will, intention and confidence; no hesitation in achieving the goals that lead to the desired purpose" (Bin Tamim, 2009, p. 2).

Abu Muammar (2016: 19) defined the strategic decisions as "exceptional decisions characterized by inclusiveness, rationality and long-term, and include a series of stages that constitute the cornerstone of the success of business organizations; any error that occurs in it will expose the organization to significant risks. Therefore the organizations seek to keep these decisions away from the impact of the external authorities or authorities that have certain powers, with the need to take into account the decentralization when making those decisions.

Understanding strategic decision-making as an organized process of information gathering and processing and evaluating it is a part of the process of transferring knowledge and information into the administrative activities (Ghaliah, 2015).

The literature on the issues related to the decision-making in organizations has contributed in identifying two of the basic approaches of decision-making: analytical and intuitive; These methods, which are based on the principles of the main behavioral decision theories, explain how the organization's decision-making reflects the different behaviors of decision-makers regarding their way of thinking and perception of the environment as a whole, understanding the different internal and external variables and their interactions, interpreting events and paying attention to the way in which activities are carried out and looking into the potential results in order to achieve certain objectives (Habaradas, 2009).

The analytical approach refers to decision-making based on formal analysis. Whereas the intuitive approach refers to decision-making based on general knowledge, experience and available information, but without the support of the formal analysis (Goll \& Racheed, 2005).

In general, when it comes to strategic decision-making, researchers have given preference to analytical decision-making over the obvious decision-making. One of the basic hypotheses is that the systematic analysis and caution leads to the choices that go beyond the result from the intuitive processes (Al-Shammari et. al., 2013).

Khatri \& $\mathrm{Ng}$ (2000) emphasized that the improvement of the intellectual knowledge and artificial intelligence show that there is no mystical or magical thing about intuitive processes. Moreover, the researchers emphasized that intuitive processes develop from long experience and learning and consist of a mass of facts, patterns, concepts and technologies, and generally the so-called formal knowledge or beliefs.

The researcher defines strategic decision making as a long-term decision that determines the ways of achieving the company's strategic objectives.

The characteristics of the strategic decision:

Several researchers noted that the strategic decision has several characteristics. Oliver (2012) listed four main characteristics:

- These decisions are likely to be related to or affecting the long-term direction of the organization.

- Strategic decisions are usually about trying to achieve some benefits for the organization.

- Strategic decisions are likely to be specified by the scope of the activities and the addressing of the issue, whether the organization should focus on one area of activity or it should have more than one. 
- The scope of the activities determines how the managers understand the boundaries of an organization.

The other characteristics of the strategic decisions are: firstly, the centralization; where decision is made at the highest administrative level. Secondly, long-standing; the strategic decision covers a long period of time. Thirdly, guidance; strategic decisions provide guidelines for other decisions.. Fourthly, the high cost; the process of making and implementing strategic decisions requires considerable funds and obligation. Fifthly, the inevitability; the strategic decision is an inevitable decision that the organization must make in order to be able to build other administrative decisions (Wissam, 2015).

The researcher believes that the most important characteristics of the strategic decision is that it is a very important decision, therefore it should be made at the highest levels of leadership after passing through the decision-making stages, and it can be described as a long-term process and has an impact on the organization and its viability and must be consistent with the organization's vision, mission and strategic objectives.

\subsection{Competitive Capability}

Economic institutions have witnessed a number of developments in many areas starting from the new data that occurred in the competitive environment to the data of the change that has swept all fields, especially in the field of business, which made managers look for a new structure of ideas and administrative methods that fit the current situation in order enable their organizations to gain and maintain competitive capability as it is the way to its integration into the world economy, its growth and survival in the market (Bin Za'atar \& Madinah, 2016).

The issue of competitiveness is being taken over by a wide debate among politicians, businessmen and economists. This is clearly shown due to the existence of distinction in the exact meaning of the term "competitive capability" among these groups. The main source of this distinction is the divergence of views on the possibility of finding ways to measure competitive capability. Economists and politicians always think of the term "competitive capability" in the context of the economy as a whole unlike business men who focus only on institutions and sectors (Al-Hajraf, 2011).

Hamdi (2005) pointed out that the small countries are more able to benefit from the concept of competitiveness in all its meanings than large countries, as it gives the organizations or companies of the small countries the opportunity to get out from the limited small market to the global market. This means that the concept of competitive capability carries a lot of data, indicators, dimensions and characteristics that make this concept goes beyond the good use of all possible resources. It goes beyond that to draft an offensive and defensive strategies that are difficult for the competitors to follow.

The concept of competitive capability:

Siudek and Zawojska (2014) pointed out that the term "competitive capability" was one of the most widely used concepts in economics but it is not sufficiently accurate, which meant that there was no generally accepted definition for the competitive capability. Today, it is usually used in different contexts.

Arslan and Tatlıdil (2012) defined it as an organization's ability to produce goods and services that meet the needs of international markets while maintaining and expanding real incomes, as well as raising the welfare of its employees.

Competitiveness has been defined as "the ability to make profits consistently and to acquire an appropriate market share. It is an indicator of the performance of domestic products in municipal and foreign markets compared to similar foreign goods and services. This applies to exports in terms of their ability to penetrate the global markets and compete with similar items. It also applies to the ability of the national industry to compete with imported items in the local market" (Al-Hajraf, 2011: 40).

Competitive capability is also considered a ability or an element of superiority for an organization that is achieved if it follows a certain competitive strategy (Bin Za'atar \& Madinah, 2016).

The researcher defines competitive capability as the ability of the organization to provide a service or product that is distinguished from other competing products in terms of quality, design and price, and it possesses a high market share.

The importance of competitiveness:

Al-Senoussi (2016) pointed out that the importance of competitiveness is highlighted in several points: firstly, its importance in the study of the strategic management, where the studies and research within the strategy and its management are not devoid of the concept of competitiveness. Secondly, competitiveness is considered an important and essential factor for the work of the organizations as they are the basis of the inclusive competitive strategy of the organization. Thirdly, competitiveness is an instrument that is used to meet the challenge which the 
organization expects from its competitors, by developing its competitive knowledge and its ability to meet the needs of the customers in the future.

Finally, competitive capability is an important criterion for successful and distinct organizations, as these organizations develop new models, ideas, goods and services that develop their competitiveness consistently.

The researcher believes that the competitive capability has the same importance of the viability of the organization, the continuity of profit and development. The researcher also believes that competitive capability enables the organization to increase its market share continuously.

\section{The Methodology of the Study}

The descriptive approach: This study follows the descriptive approach with the aim of identifying and describing the variables of the study and indicating its directions. The study also follows the descriptive approach to describe the nature of problem of the study and its analysis.

The analytical approach: This study follows an analytical approach that is based on the study, analysis and interpretation of the relations that exists between the variables of the strategic decision making and competitiveness variables.

\subsection{Study Sample}

The number of the employees in the Royal Jordanian Airlines is 4135 (the annual report of Royal Jordanian Airlines, 2017). The intentional sample method was used where the study tool was distributed to (150) employees of various levels of management in the company.167 questionnaires were distributed to the members of the study sample, 164 were retrieved and after careful consideration, 3 questionnaires were neglected for incomplete answers. Accordingly, 161 questionnaires were submitted. Then the data were entered into the computer, and the descriptive statistical analysis, which is represented in the repetition, proximity, the arithmetic mean and the standard deviation of the questionnaire sections, and the regression test of the study hypothesis, were carried out at a level of statistical significance of $(0.05 \geq \alpha)$.

The study examined a number of demographic variables for the sample of the study in terms of gender, age, educational qualification and number of years of experience. The study was based on the general information included in the questionnaire as follows:

Table 1. Describes the study sample according to the demographic variables of the study members

\begin{tabular}{llll}
\hline The variable & Level / category & Repetition & Percentage (\%) \\
\hline Gender & Male & 97 & $60.2 \%$ \\
& Female & 64 & $39.8 \%$ \\
Age & Total & 161 & $100 \%$ \\
& From 25 to 30 years old & 34 & $21.1 \%$ \\
& More than 30 - 35 years & 69 & $42.9 \%$ \\
& More than 35 - 40 years & 38 & $23.6 \%$ \\
& More than 40 - 45 years & 20 & $12.4 \%$ \\
Educational qualification & Total & 161 & $100 \%$ \\
& Intermediate diploma or less & 12 & $7.5 \%$ \\
& Bachelor's degree & 122 & $75.8 \%$ \\
& Master's degree & 25 & $15.5 \%$ \\
& PhD & 2 & $1.2 \%$ \\
& Total & 161 & $100 \%$ \\
Number of years of experience & $1-3$ years & 28 & $17.4 \%$ \\
& More than 3-6 years & 71 & $44.1 \%$ \\
& More than 6-9 years & 35 & $21.7 \%$ \\
& More than 6-12 years & 19 & $11.8 \%$ \\
& More than 12 years & 8 & $5.0 \%$ \\
& Total & 161 & $100 \%$ \\
\hline
\end{tabular}

Table 1 indicates that the percentage of males reached (60.2\%) of the sample of the study. The table also indicates that the highest percentage in the age group was for the category (more than $30-35$ years) and by $42.9 \%$. The highest percentage was among the holders of the bachelor's degree $(75.8 \%)$. In the number of years 
of experience, the category (more than 3-6 years) was the largest group (44.1\%).

\subsection{Sources of Gathering Data}

1 - Secondary sources: These sources provide the researcher with indirect data on the subject, and represent the information and the data needed to form an integrated scientific background on the subject of study. This information and secondary data were collected through a scientific survey on the subjects related to the variables of the study model.

2 - Preliminary sources: Here the study instrument has been relied upon (questionnaire), which was prepared for the study.

\subsection{The Instrument of the Study}

The instrument of the study consists of a questionnaire that is constructed and designed to include the following parts:

Part 1: aims at identifying the demographic factors of responders in terms of age, qualification, and experience.

Part 2: includes paragraphs covering the variables of the independent study, which is represented in the variables of the decision-making (the determination of the problem, the gathering of the information on the problem, decision-making, the monitoring of the implementation of the decision-making, and the circulation of the realistic results of the decision).

Part 3: includes paragraphs related to the dependent variable of (competitive capability).

\subsection{The reliability of the Instrument and It Stability}

1) The researcher checked the validity of the instrument of the study by presenting it on a group of arbitrators and specialists in the fields of business administration, scientific research methodology and statistics. Their views were considered in the modification of the instrument.

2) The stability was tested, which is represented in the calculation of the (Cronbach- alpha) coefficient, in order to test the internal consistency of the areas covered by the questionnaire as a measurement tool.

Table 2. Cronbach- alpha coefficients of the topics of the study.

\begin{tabular}{llll}
\hline & & & \\
Number & Topic & Number of paragraphs & Cronbach- alpha coefficient \\
& & & \\
\hline \multicolumn{2}{l}{ Strategic decision-making } & 21 & \\
1 & Identifying the problem & 3 & 0.737 \\
2 & Gathering information about the problem & 3 & 0.951 \\
3 & Decision-making & 6 & 0.623 \\
4 & Monitoring the implementation of decision-making & 5 & 0.821 \\
5 & Circulating the results & 4 & 0.757 \\
Competitiveness & 14 & 0.893 \\
\multicolumn{2}{l}{ The instrument as a whole } & 35 & \\
\hline
\end{tabular}

Table 2 shows that all stability coefficients are high and acceptable for the purposes of the study, where the stability coefficient (Cronbach'-alpha) is more than (0.60).

The Cronbach-Alpha coefficient of the instrument of the study as a whole was $(0.912)$, thus confirming the stability of the questionnaire and its internal consistency.

\subsection{Statistical Methods}

Descriptive statistical measurement was used to describe the research population and its sample, and to determine its characteristics by depending on percentages and repetitions, and to arrange the variables of research according to their relative importance by depending on the values of the arithmetic mean and the standard deviations.

In order to test the hypotheses of the study, (multi regression) analysis was adopted.

\section{Data Analysis \& Discussion}

\subsection{The Results of the Descriptive Statistics}


The sample of the study was analyzed to assess the degree of its rating of the phrases related to the impact of the strategic decision-making in enhancing competitive capability. The arithmetic means and the standard deviations of the fields of the study were calculated as follows:

\subsection{Strategic Decision-Making}

Table 3 refers to the variables of strategic decision making where the arithmetic means for all the subjects of the strategic decision-making were calculated and were ranked in a descending order, and were arranged according to the degree of the rating. The results were as follows:

Table 3. The variables of the strategic decision-making have been arranged in a descending order according to the degree of the rating

\begin{tabular}{llll}
\hline The issue & The arithmetic mean & Standard deviation & Rank \\
\hline The circulation of the realistic results of the decision & 3.823 & 0.995 & High \\
The monitoring of the implementation of the decision-making & 3.776 & 0.965 & Medium \\
The determination of the problem & 3.666 & 0.766 & Medium \\
Decision-making & 3.523 & 0.928 & Medium \\
The gathering of the information on the problem & 3.458 & 0.886 & Medium \\
Strategic decision-making & 3.649 & 0.908 & Medium \\
\hline
\end{tabular}

Table 3 refers to the arithmetical means, the standard deviations and the rank of the strategic decision-making variables. The table also indicates that the strategic decision making has an average rating equals (3.649).

The table also indicates that the circulation of the results was in the first place with an average of (3.823) and a standard deviation of (0.995) and a high degree of rating, followed by the monitoring of the implementation of the decision with an average of (3.776) and a standard deviation of (0.965). The determination of the problem came in third place with an average of (3.666) and a standard deviation of (0.766) and a medium degree of rating. It was followed by decision-making with an average of (3.523) and a standard deviation of (0.928). The gathering of the information on the problem came in the last place with an arithmetic mean of (3.458) and a standard deviation of (0.886).

\subsection{Competitive Capability}

Table 4. The arithmetic means, standard deviations, and the rating of the topic's paragraphs

\begin{tabular}{|c|c|c|c|c|c|}
\hline $\begin{array}{l}\text { Paragraph } \\
\text { no. }\end{array}$ & Paragraph & $\begin{array}{l}\text { Arithmetic } \\
\text { mean }\end{array}$ & $\begin{array}{l}\text { Standard } \\
\text { deviation }\end{array}$ & Ranking & Rating \\
\hline 22 & The company has an inclusive future vision. & 3.383 & 0.984 & 4 & High \\
\hline 23 & $\begin{array}{l}\text { The company's strategy is flexible and adaptable according to the } \\
\text { variables of the surrounding environment. }\end{array}$ & 3.963 & 0.697 & 2 & High \\
\hline 24 & $\begin{array}{l}\text { The company's inclusive strategy adopts a strategic information } \\
\text { system capable of dealing with the indicators of the business } \\
\text { environment. }\end{array}$ & 4.040 & 0.958 & 1 & High \\
\hline 25 & $\begin{array}{l}\text { The company's strategy is able to keep pace with any technological } \\
\text { change and dynamic development. }\end{array}$ & 3.621 & 1.043 & 5 & Medium \\
\hline 26 & $\begin{array}{l}\text { The company analyzes its environment to identify strengths and } \\
\text { weaknesses. }\end{array}$ & 3.926 & 0.771 & 3 & High \\
\hline 27 & $\begin{array}{l}\text { The company analyzes its environment to know the opportunities and } \\
\text { threats. }\end{array}$ & 3.168 & 1.068 & 13 & Medium \\
\hline 28 & $\begin{array}{l}\text { The company has the ability to shift from one strategy to another at } \\
\text { any time in accordance with the internal and external environmental } \\
\text { changes. }\end{array}$ & 3.323 & 0.912 & 11 & Medium \\
\hline 29 & $\begin{array}{l}\text { The company's strategy deals seriously with the environmental } \\
\text { indicators to improve its current investment into what it should be. }\end{array}$ & 3.522 & 0.902 & 7 & Medium \\
\hline 30 & $\begin{array}{l}\text { The company's management has the ability to predict the actions of } \\
\text { the competitors. }\end{array}$ & 3.050 & 0.927 & 14 & Medium \\
\hline 31 & The company examines the characteristics and trends of the customer & 3.391 & 0.845 & 8 & Medium \\
\hline 32 & The company seeks to meet the needs and wishes of the customers. & 3.348 & 0.989 & 9 & Medium \\
\hline 33 & The company provides the qualified employees. & 3.217 & 1.017 & 12 & Medium \\
\hline 34 & $\begin{array}{l}\text { The company develops the capabilities of its employees in order to } \\
\text { achieve its objectives. }\end{array}$ & 3.335 & 0.968 & 10 & Medium \\
\hline 35 & The company develops the planning skills of the employees. & 3.603 & 0.944 & 6 & Medium \\
\hline
\end{tabular}




\begin{tabular}{llll}
\hline The total average of the paragraphs & 3.515 & 0.930 & Medium
\end{tabular}

Table 4 shows that competitiveness has a medium rating, where the arithmetic mean of the topic reached (3.515). It is noted from the table that the arithmetical means of the views of the members of the study sample on the paragraphs of the topic ranged between (3.050-4.040) with a rating ranging from medium to high.

The table also indicates that paragraph (24), which states that "The Company's inclusive strategy adopts a strategic information system capable of dealing with the indicators of the business environment." had the highest level of rating with an average of (4.040) and a high degree of rating.

Paragraph (30), which states that "The Company's management has the ability to predict the actions of the competitors" had the lowest level of ranking with an average of (3.050) and a medium degree of rating.

\subsection{The Results of Testing the Hypotheses}

\subsubsection{The Main Hypothesis}

There is a statistically significant impact at the level $(0.05 \geq \alpha)$ ) for strategic decision-making (the determination of the problem, the gathering of the information on the problem, decision-making, the monitoring of the implementation of the decision-making, and the circulation of the realistic results of the decision) in enhancing the competitive capability of the Royal Jordanian Airlines.

In order to test the first main hypothesis of the study, the regression test was conducted to show whether there is a statistically significant impact at the level of $(\leq 0.05)$ for strategic decision-making in enhancing the competitive capability of the Royal Jordanian Airlines.

The results of analyzing the multi regression test:

Table 5. Model summary

\begin{tabular}{lllll}
\hline Std. Error of the Estimate & Adjusted R Square & R Square & R & Model \\
\hline 0.40923 & 0.493 & 0.509 & 0.714 & 1 \\
\hline
\end{tabular}

a. Predictors: (Constant), (the determination of the problem, the gathering of the information on the problem, decision-making, the monitoring of the implementation of the decision-making, and the circulation of the realistic results of the decision)

Table 5 indicates that the correlation coefficient between the independent variable and the dependent variable is (0.714), as shown. The coefficient of determination(R Square) was (0.509), so the independent variable (strategic decision-making) was able to explain $(50.9 \%)$ of the changes that occurred in the dependent variable.

Testing the significance of multiple regression model:

Table 6 presents the results of the variation (ANOVA) analysis of testing the intangibility of the regression test:

Table 6. The results of the variation analysis

\begin{tabular}{llllll}
\hline Model & Sum of Squares & DF & Mean Square & F & Sig. \\
\hline Regression & 26.944 & 5 & 5.389 & 32.177 & $.000^{\mathrm{b}}$ \\
Residual & 25.958 & 155 & 0.167 & & \\
Total & 52.902 & 160 & & & \\
\hline
\end{tabular}

a. Dependent Variable: competitive capability.

b. Predictors: (Constant), (the determination of the problem, the gathering of the information on the problem, decision-making, the monitoring of the implementation of the decision-making, and the circulation of the realistic results of the decision)

Table 6 shows the variation analysis, which aims at identifying the explanatory power of the model and the variable (the strategic decision-making) in enhancing the competitive capability) through statistical analysis (F).

As shown in Table 6, it is clear that there is a big intangible significance for F, estimated at $(32,177)$, which is higher than its table value (1.16), with a significance level of ( $\mathrm{Sig}=0.000)$ which is lower than the significance level $(0.05 \geq \alpha)$. Thus, the regression model has an appropriate intangible relation to measure the causal relationship between the independent variable and the dependent variable. 
In this sense, the zero hypothesis is accepted and the alternative hypothesis are rejected which states that the regression model is intangible (there is an impact for independent variables on the dependent variable).

This means that, there is a statistically significant impact at the level of $(0.05 \geq \alpha)$ for strategic decision-making (the determination of the problem, the gathering of the information on the problem, decision-making, the monitoring of the implementation of the decision-making, and the circulation of the realistic results of the decision) in enhancing the competitive capability of the Royal Jordanian Airlines. The result is generally consistent with the study of El-Hajraf (2011), which indicated that the Organization's strategy has a high impact in improving the competitive capability of Kuwaiti commercial banks.

Multiple regression equation coefficients:

Table 7 shows the values of the regression coefficients and their statistical tests as shown below:

Table 7. Regression coefficients of the independent variables of strategic decision-making (the determination of the problem, the gathering of the information on the problem, decision-making, the monitoring of the implementation of the decision-making, and the circulation of the realistic results of the decision) in enhancing the competitiveness

\begin{tabular}{|c|c|c|c|c|c|}
\hline \multirow[t]{2}{*}{ Model } & \multicolumn{2}{|c|}{ Unstandardized Coefficients } & \multicolumn{2}{|l|}{ Standardized } & \multirow[b]{2}{*}{ Sig. } \\
\hline & B & Std. Error & $\begin{array}{l}\text { Coefficients } \\
\text { Beta }\end{array}$ & $\mathrm{t}$ & \\
\hline Constant & 0.105 & 0.389 & & 0.269 & 0.788 \\
\hline $\begin{array}{l}\text { The determination of the } \\
\text { problem }\end{array}$ & 0.041 & 0.054 & 0.044 & 0.752 & 0.453 \\
\hline $\begin{array}{l}\text { The gathering of the } \\
\text { information on the problem }\end{array}$ & 0.094 & 0.040 & 0.139 & 2.366 & 0.019 \\
\hline decision-making & 0.156 & 0.054 & 0.182 & 2.858 & 0.005 \\
\hline $\begin{array}{l}\text { The monitoring of the } \\
\text { implementation of the } \\
\text { decision-making }\end{array}$ & 0.090 & 0.050 & 0.116 & 1.810 & 0.072 \\
\hline $\begin{array}{l}\text { The circulation of the } \\
\text { realistic results of the } \\
\text { decision }\end{array}$ & 0.533 & 0.050 & 0.702 & 10.681 & 0.000 \\
\hline
\end{tabular}

First sub-hypothesis:

- There is a statistically significant impact at the level $(0.05 \geq \alpha)$ for the determination of the problem in the enhancement of the competitive capability of the Royal Jordanian Airlines.

Table 7 shows that, there is no statistically significant impact at the level of $(0.05 \geq \alpha)$ for (The determination of the problem) in enhancing the competitive capability of the Royal Jordanian Airlines. The value of $t$ is $(0.752)$ which is less than the table value $(1,962)$, and the level of significance is $(0.453)$,which is above the significance level of $(0.05 \geq \alpha)$. Thus the zero hypothesis is rejected and the alternative hypothesis is accepted.

This means that there is no statistically significant impact at the level of $(0.05 \geq \alpha)$ for (the determination of the problem) in enhancing the competitive capability of the Royal Jordanian Airlines.

Second sub-hypothesis:

- There is a statistically significant impact at the level $(0.05 \geq \alpha)$ for the gathering of the information on the problem in the enhancement of the competitive capability of the Royal Jordanian Airlines.

Table (7) shows that, there is a statistically significant impact at the level of $(0.05 \geq \alpha)$ for (The gathering of the information on the problem) in enhancing the competitive capability of Jordanian Airlines. The value of (t) is (2.366), which is higher than the table value $(1,962)$, and the significance level is $(0.019)$, which is less than the significance level $(0.05 \geq \alpha)$. Thus, the zero hypothesis is accepted and the alternative hypothesis is rejected.

This means that there is a statistically significant impact at the level of $(0.05 \geq \alpha)$ for (the gathering of the information on the problem) in enhancing the competitive capability of the Royal Jordanian Airlines.

Third sub-hypothesis:

-There is a statistically significant impact at the level $(0.05 \geq \alpha)$ for the decision making in the enhancement of 
the competitive capability of the Royal Jordanian Airlines.

Table (7) shows that, there is a statistically significant impact at the level of $(0.05 \geq \alpha)$ for (the decision-making) in enhancing the competitive of capability of the Royal Jordanian Airlines. The value of $t$ is (2.858) which is higher than the table value $(1,962)$ and the level of significance is $(0.005)$ which is lower than significance level $(0.05 \geq \alpha)$.Thus the zero hypothesis is rejected and the alternative hypothesis is accepted.

This means that there is a statistically significant impact at the level of $(0.05 \geq \alpha)$ for decision-making in enhancing the competitive capability of the Royal Jordanian Airlines.

Fourth sub-hypothesis:

- There is a statistically significant impact at the level $(0.05 \geq \alpha)$ for the monitoring of the implementation of the decision-making in the enhancement of the competitive capability of the Royal Jordanian Airlines.

Table (7) shows that, there is no statistically significant impact at the level of $(0.05 \geq \alpha)$ for (the monitoring of the implementation of the decision-making) in enhancing the competitive capability of the Royal Jordanian Airlines. The value of $t$ is $(1.810)$ which is less than the table value $(1,962)$, with a level of significance $(0.072)$ which is higher than the level of significance $(0.05 \geq \alpha)$. Thus the zero hypothesis is rejected and the alternative hypothesis is accepted.

This means that there is a statistically significant impact at the level of $(0.05 \geq \alpha)$ for (the monitoring of the implementation of the decision-making)in enhancing the competitive capability of the Royal Jordanian Airlines.

Fifth sub-hypothesis:

-There is a statistically significant impact at the level $(0.05 \geq \alpha)$ for the circulation of the realistic results of the decision in the enhancement of the competitive capability of the Royal Jordanian Airlines.

Table (7) shows that there is a statistically significant impact at the level $(0.05 \geq \alpha)$ for the circulation of the realistic results of the decision in the enhancement of the competitive capability of the Royal Jordanian Airlines .The value of $(t)$ is (10.681) which is higher than the table value (1.962), with a significance level of $(0.000)$ which is lower than the significance level of $(0.05 \geq \alpha)$. Thus, the zero hypothesis is accepted and the alternative hypothesis is rejected.

This means that there is a statistically significant impact at the level $(0.05 \geq \alpha)$ for the circulation of the realistic results of the decision in the enhancement of the competitive capability of the Royal Jordanian Airlines.

\subsection{Discussion}

The results indicated that there was a medium rating for the strategic decision-making with an arithmetic mean of (3.649). It was found that the circulation of the results was in the first place with a high degree of rating. The monitoring of the implementation of the decision-making came in the second place with a high degree of rating. The determination of the problem came in the third place with a medium degree of rating .The decision-making came in the fourth place. The gathering of the information came in the last place with a medium degree of rating. The results also indicate that the competitive capability of the Royal Jordanian Airlines has an average level, which indicates that there is no effective and efficient strategic planning, and there is no competitive capability at a high level.

The study indicated that the determination of the problem has a medium level, where its arithmetic mean was (3.666), and the mean averages for the subjects of the sample ranged from(3.302-3.981), ) with a medium to high ratting.

The study showed that paragraph (3), which states that "the problem is classified according to its type and importance", had the highest rating with an average of (3.981). Whereas paragraph (1), which states that "the problem is determined in order to make a decision", had a lower rating with an average of (3.302) with a medium ratting.

The study also indicated that the issue of gathering the information had a medium level. Its arithmetic mean was (3.458),where the mean of the views of the members of the study sample ranged from 3.280 to 3.590 with a medium rating for all issues.

The results indicated that the decision-making had a medium level, where its mean was (3.523). It is noted from the table that the statistical averages of the views of the members of the study sample on the paragraphs of the issue ranged between (3.329 - 3.839) with a rating ranging from medium to high. The result is consistent with the findings of study of Hamza (2008), which indicated that the strategic decisions made to increase capital was not successful and formed a burden on the bank more than a benefit to it .In addition to the lack of an inclusive strategy 
that specifies the work of the bank, thus the strategic decisions in the field of investment is inefficient which results in realizing weak results.

The results indicated that paragraph (12), which stipulates that "the decision is made after considering all the alternatives and choosing the best", had the highest level of rating with an arithmetic mean of (3.839) and a high degree of rating. Whereas paragraph (7), which stipulates that "the establishment of effective alternatives in line with the reality of the company and its potential ability ", had the lowest level with an average of (3.329) and a medium degree of rating.

There was a high level of rating for the issue of monitoring the implementation of the decision-making, where its arithmetic mean was (3.776). It is noted from the table that the arithmetic means of the views of the members of the study sample on the paragraphs of the issue ranged between (3.447 - 3.969) with a degree of rating ranging from medium to high.

The results also indicated that paragraph (17), which stipulates that "the results of the implementation of the resolution are reviewed consistently", had the highest level with an arithmetic mean of (3.969) and a high degree of rating. The table also indicates that paragraph (15), which states that "there is a clear mechanism for detecting and correcting deviations," had the lowest level of rating with an arithmetic mean of (3.447) and a medium degree of rating.

The results also indicated a statistically significant impact for (the gathering of the information, decision-making, and the circulation of the realistic results of the decision) in enhancing the competitive capability of the Royal Jordanian Airlines.

In the light of the results, the study recommends the need to work on raising the level of efficiency of the strategic decision-making, especially in terms of the determination of the problem, and to develop effective alternatives in line with the reality of the company and its available possibilities, and to find a clear mechanism that includes the detection of deviations and correcting them, and improving the ways of decision-making.

\section{Conclusions \& Recommendations}

The results of this study showed there was a medium rating for the strategic decision-making. It was found that the circulation of the results was in the first place with a high degree of rating. The monitoring of the implementation of the decision-making came in the second place with a high degree of rating. The determination of the problem came in the third place with a medium degree of rating. The decision-making came in the fourth place. The gathering of the information came in the last place with a medium degree of rating. The results also showed that the competitive capability of the Royal Jordanian Airlines has an average level, which indicates that there is no effective and efficient strategic planning, and there is no competitive capability at a high level.

The results also indicated a statistically significant impact for (the gathering of the information, decision-making, and the circulation of the realistic results of the decision) in enhancing the competitive capability of the Royal Jordanian Airlines.

In the light of the results, the Royal Jordanian Airlines should:

- Work on raising the level of efficiency of the strategic decision-making, especially in terms of the determination of the problem.

- Develop effective alternatives in line with the reality of the company and its available possibilities.

- Find a clear mechanism that includes the detection of deviations and correcting them, and improving the ways of decision-making.

\section{References}

Abu, M., \& Tahani, F. (2016). The role of Knowledge Management in Strategic Decision-making: An Empirical Study on the Managers of the UNRWA in the Gaza Strip. Unpublished Master's Thesis, Al-Aqsa University.

Ahmed, A., Bwisa, H., Otieno, R., \& Karanja, K. (2014). Strategic Decision Making: Process, Models, and Theories. Business Management and Strategy, 5(1), 78-104. https://doi.org/10.5296/bms.v5i1.5267

Al-Otoum, M. F. (2009). The Message of the Organization and its impact in achieving the competitive advantage: A field study on the Jordanian pharmaceutical industry. Unpublished Master's thesis, Middle East University for Postgraduate Studies.

Al-Shamri, S. R., El-Azzawi, B. M., \& Al-Mashhadani, A. A. Q. (2013). The impact of some strategic factors in making rational decisions: A field study on a sample of Iraqi ministries. Journal of Baghdad College for Economic Sciences University, (34), 67-86. 
Arslan, N., \& Tatlidil, H. (2012). Defining and Measuring Competitiveness: A Comparative Analysis of Turkey with 11 Potential Rivals. International Journal of Basic \& Applied Sciences, 12(2), 31-43.

Ben, T., Dahi, K. (2009). The strategic leader and decision-making, the scientific seminar for the employees of the General Directorate of border guards called "The development of the strategic skills of the leaders" during the period 14-18 / 3/2009 in Riyadh.

Ben Za'tar, A., \& Madni, A. (2016). The Role of the Change in improving the Competitiveness: A Case Study of the Success Milk Mughniyeh foundation. Unpublished Master's Thesis, University of Abu Bakr Belqayd.

Elbanna, S., \& Child, J. (2007). The influence of decision, environmental and firm characteristics on the rationality of strategic decision-making. Journal of Management Studies, 44(4), 561-591.

El-Ghalibi, T. M. (2012). Entries of the Strategic Decision Making and its relationship to Performance: An Empirical Study on Iraqi Organizations. Journal of Economic Sciences, 29(8), 80-112.

El-Hajraf, H. M. (2011). The Impact of the Organization's Strategy in improving the Competitiveness of Kuwaiti Commercial Banks. Unpublished Master's Thesis, Middle East University.

Esmaeili, M. (2014). A Study on the Effect of the Strategic Intelligence on Decision Making and Strategic Planning. International Journal of Asian Social Science, 4(10), 1045-1061.

Ghaleiah, F. (2015). The Impact of Information and Communication Technologies on Strategic Decision Making: Case Study of Al-Ziban Mills "Al-Qantara" in Soukra. Unpublished Master's Thesis, Mohammed Khedr Universityin Soukra.

Gigerenzer, G. (2001). Decision making: Non-rational theories. International Encyclopedia of the Social and Behavioral Sciences, 5, 3304-3309. https://doi.org/10.1016/b0-08-043076-7/01612-0

Goll, I., \& Rasheed, A. (2005). The Relationships between Top Management Demographic Characteristics, Rational Decision making, Environmental Munificence, and Firm Performance. Organization Studies 26(7), 999-1023. https://doi.org/10.1177/0170840605053538

Habaradas, R. (2009). Organizational learning in SMEs: Literature review and proposed methodological approach. 6th Asialics International Conference - Linkages in Innovation Systems: Global and Local Perspective.

Hamdi, A. H. (2015). The role of the Functional Competencies in enhancing the Competitive Strategy for Contemporary Organizations: A Case Study of Riyad Setif. The Oasis Mills Unit, Foundation in Touggourt and Ouargla, Unpublished Master's Thesis, Mohammed Khedr University in Soukra.

Hamoud, Z. M. (2015). The competitiveness of the Syrian cotton products in the framework of the liberalization of the international trade. Unpublished doctoral theses, University of Damascus.

Hamza, H. (2008). The relation between the strategic decision and the banking performance: Analytical study. Journal of Administration and Economics, 68, 78-95.

Issani, A., \& Gabri, J. (2016). The Role of the decision support systems in the strategic decision-making in the economic institutions. Unpublished master's thesis, EL-Arabi El-Tebsi University in Tébessa.

Issawy, K. A. (2015). Training and its impact in the rational administrative decisions-making: A survey on the views of a sample of general managers in Iraq. Journal of Qadisiyah for Administrative and Economic Sciences, 17(1), 33-49.

Ivan, M., \& Ivana, B. (2012). The Nature of Strategic Decision Making - Exploiting the role of managers' incremental and radical learning. The Journal of International Management Studies, 7(2), 7-19.

Khatri, N., \& Ng, A. H. (2000). The Role of Intuition in Strategic Decision Making. Human Relations, 53(1). 57-86. https://doi.org/10.1177/0018726700531004

Lalaimia, M. A. (2015). The Importance of Strategic Intelligence in the Decision Making Process, a Field Study in the Ferital Foundation. Unpublished Master's Thesis, Mohammed Khedr University in Soukra.

Munir, N. (2006). Analyzing the Arab competitiveness in the light of the economic globalization. Journal of North African Economics, 3(4), 21-48.

National Portfolio Securities Plc. (2009). Aliah - Royal Jordanian Airlines, Department of Studies and Research.

Oliver. (2012). The characteristics of strategic decisions. Retrieved from https://www.eddielogic.com/2012/12/28/the-characteristics-of-strategic-decisions/ 
Peixoto, L., Golgher, A., \& Cyrino, A. (2013). Using Information Systems to Strategic Decision: An Analysis of the Values Added Under Executive's Perspective. Brazilian Journal of Information Studies: Research Trends, 11(1), 54-71.

Sinousi, I. W. (2016). The Impact of the Government in achieving the competitive advantage. Unpublished Master's Thesis, Middle East University.

Siudek, T., \& Zawojska, A. (2014). Competitiveness in the Economic Concepts. Theories and Empirical Research, Oeconomia, 13(1), 91-108.

Wesam, N. (2015). Knowledge Management and its Role in Enhancing the Strategic Decision-Making: A Case Study of the institution of Constructing Metal Structures. Oum El Bouaghi Unit, Unpublished Master's Thesis, Oum El Bouaghi University.

\section{Copyrights}

Copyright for this article is retained by the author(s), with first publication rights granted to the journal.

This is an open-access article distributed under the terms and conditions of the Creative Commons Attribution license (http://creativecommons.org/licenses/by/4.0/). 